\title{
Classification of gluteal muscle contracture in children and outcome of different treatments
}

\author{
Chen-Guang Zhao, Xi-Jing He*, Bin Lu, Hao-Peng Li, Dong Wang and Zhen- \\ Zhong Zhu
}

Address: Department of Orthopaedic Surgery, The 2nd Affiliated Hospital of Medical College, Xi'an JiaoTong University, Xi'an, Shaanxi, 710004, PR China

Email: Chen-Guang Zhao - Zhao_chenguang@live.cn; Xi-Jing He* - He_xijing@live.cn; Bin Lu - Lubin0008@163.com; HaoPeng Li - Li_haopeng163@163.com; Dong Wang-Wang_dong1971@163.com; Zhen-Zhong Zhu - ZZZ1129@gmail.com

* Corresponding author

Published: 7 April 2009

BMC Musculoskeletal Disorders 2009, 10:34 doi:10.1186/147/-2474-10-34

This article is available from: http://www.biomedcentral.com//47/-2474//0/34

(C) 2009 Zhao et al; licensee BioMed Central Ltd.

This is an Open Access article distributed under the terms of the Creative Commons Attribution License (http://creativecommons.org/licenses/by/2.0), which permits unrestricted use, distribution, and reproduction in any medium, provided the original work is properly cited.
Received: 27 August 2008

Accepted: 7 April 2009

\begin{abstract}
Background: Gluteal muscle contracture (GMC) is a clinical syndrome due to multiple etiologies in which hip movements may be severely limited. The aim of this study was to propose a detailed classification of GMC and evaluate the statistical association between outcomes of different management and patient conditions.
\end{abstract}

Methods: One hundred fifty-eight patients, who were treated between January 1995 and December 2004, were reviewed at a mean duration of follow-up of 4.8 years. Statistical analyses were performed using $X^{2}$ and Fisher's exact tests.

Results: Non-operative management (NOM), as a primary treatment, was effective in 19 of 49 patients (38.8\%), while operative management was effective in all 129 patients, with an excellence rating of $83.7 \%(108 / 129)$. The outcome of NOM in level I patients was significantly higher than in level II and III patients $(P<0.05)$. The results of NOM and operative management in the child group were better than the adolescent group $(P<0.05)$. Complications in level III were more than in level II.

Conclusion: NOM was more effective in level I patients than in level II and III patients. Operative management was effective in patients at all levels, with no statistical differences between levels or types. We recommend NOM as primary treatment for level I patients and operative management for level II and III patients. Either NOM or operative management should be carried out as early as possible.

\section{Background}

Gluteal muscle contracture(GMC), reported by Valderrama for the first time, is a clinical syndrome pathologically-characterized by degeneration, necrosis, and fibrosis of the gluteal muscles and fascia, leading to serious limitation of hip movements [1]. Either congenital or acquired, GMC is not uncommon and exists worldwide, involving the US, France, Italy, Poland, Australia, Spain, China, and India [2-9].

Although numerous reports have outlined the clinical features and surgical treatments for GMC, thus far the classi- 
fication of GMC, as well as the association between outcome and patient conditions, has not been described.

The purpose of this study was to propose a detailed classification of GMC and evaluate the statistical association between outcome of different management and patient conditions, including severity, pathologic type, and age by reviewing 158 of our patients over the past 10 years.

\section{Methods \\ Study population}

Between January 1995 and December 2004, 172 patients diagnosed with GMC were treated in our department. One hundred fifty-eight patients (males, 83; females, 75) 4-17 years of age, were followed for 3-8 years (average, 4.8 years). All of our studies were permitted by the Ethical Board of the 2nd Affiliated Hospital of the Medical College of Xi'an JiaoTong University, and written consent for publication was obtained from the patients or their relatives.

\section{Classification}

Based on clinical manifestations and anatomic changes, we propose a classification scheme consisting of 3 levels and 3 types (Table 1; Figures 1, 2, 3, 4, 5).

\section{Treatments}

Non-operative management (NOM)

Massage and physiotherapy, such as shortwave diathermy and hot packs, were the basic NOM techniques for patients. Following NOM, the patients could engage in the following exercises: squats with the knees close to each other, walking on a line, and moving the hips with effort. Active and passive exercise methods should be undertaken and NOM should be performed for at least last onehalf year.

\section{Operative management}

With the patient in a lateral position, a skin incision (averaging $8 \mathrm{~cm}$ ) was made at the lower part of a line between the trochanter major and the posterosuperior iliac spine. The soft tissue was dissociated until the contraction region of the gluteus maximus, which mainly existed in its upper one-half, was observed. After the gluteus maximus and the associated fascia were released, the patient was examined to determine whether the Ober's sign was positive, and if so, the gluteus medius and gluteus minimus were explored and released as well (Figure 6). Sometimes, severe cases involve even deeper parts, such as musculus piriformis, obturator internus, and the articular capsule, in which case, it should also be released and reconstructed. The sciatic nerve should be carefully protected when the deeper muscles are being released. A drainage piece or tube was placed routinely. Exercises should be carried out $24 \sim 48$ hours after the operation.

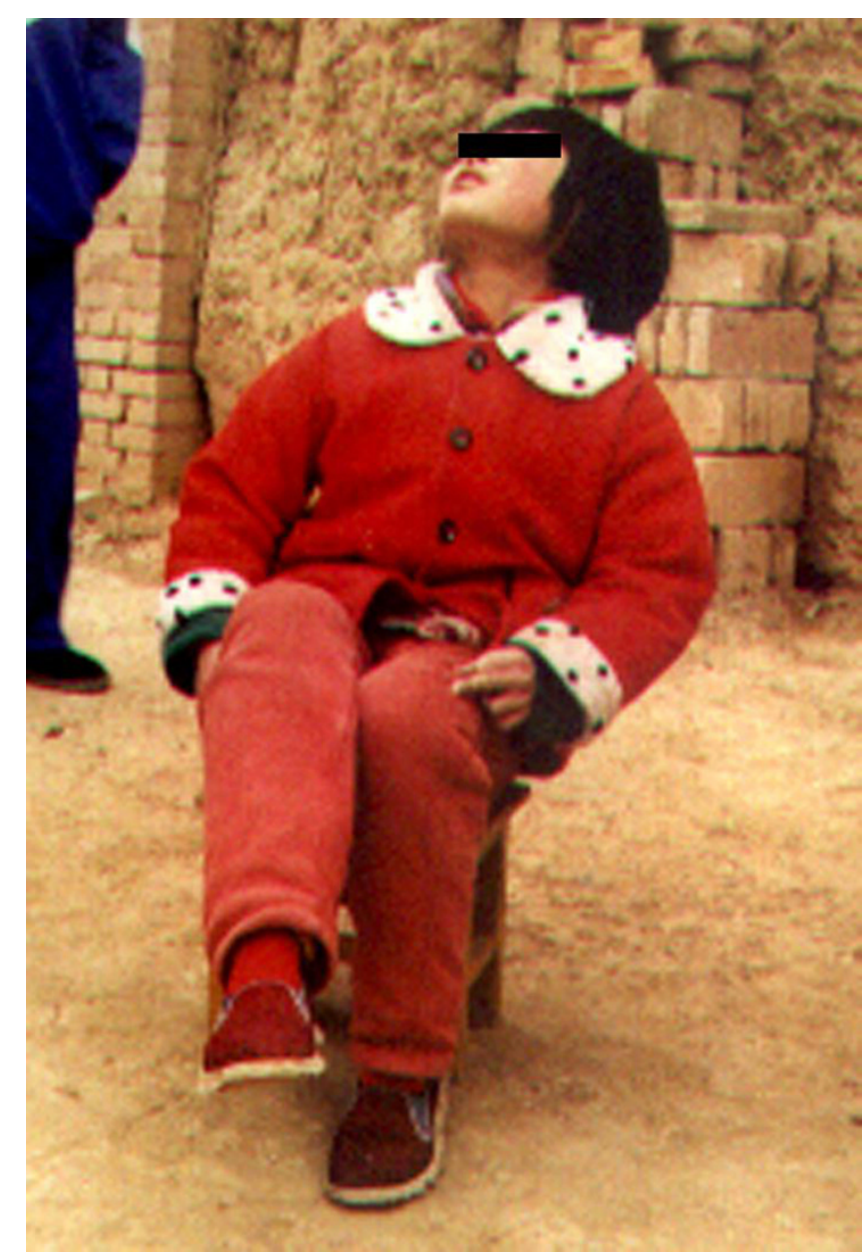

\section{Figure I}

This figure shows the functional view of a level I patient; she cannot cross her legs only.

\section{Evaluation after treatment}

Patients who completely recovered were considered to have excellent results for level I or an adduction angle that improved $>45^{\circ}$ for level $\mathrm{II}$, and $60^{\circ}$ for level III. Failure indicated that the situation was not improved or even worse, and patients needed another operative intervention. Fair result would be improved, but were not excellent.

\section{Statistics}

Statistical analyses were performed using $\mathrm{X}^{2}$ test and Fisher's exact test. A $P$ value $<0.05$ was considered statistically significant.

\section{Results}

There were 158 patients (males, 83; females, 75) diagnosed with GMC included in this study. The types of GMC were MA $(n=108,68.4 \%)$, MEI $(n=15,9.5 \%)$, and AGM $(\mathrm{n}=35,22.1 \%)$. The levels of GMC were I $(\mathrm{n}=34$, 


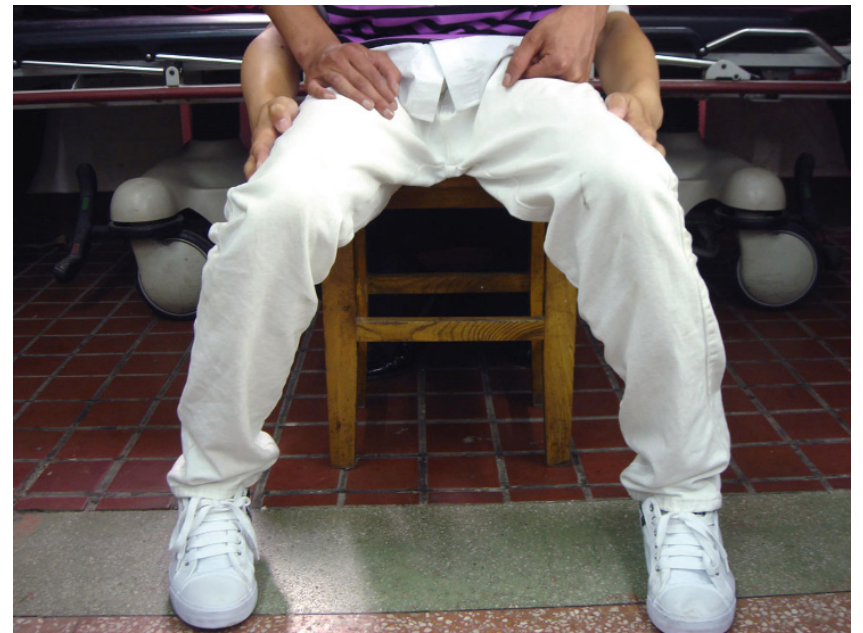

Figure 2

View of Level II patient. The abduction contracture angle is $45^{\circ}$ with both hip and knee joint in $90^{\circ}$. This patient came to our hospital for the second surgery due to the incomplete release of the contraction band in the other hospital. The huge scaring in the incision can also been seen.

$21.5 \%)$, II $(\mathrm{n}=85,53.8 \%)$, and III $(\mathrm{n}=39,24.7 \%)$; (Table 2).

All 34 level I patients, 12 of 85 level II patients, and 3 of 39 level III patients received NOM as primary treatment, which was effective in 19 patients $(38.8 \%$; Table 3$)$. The outcome of NOM in level I patients was significantly

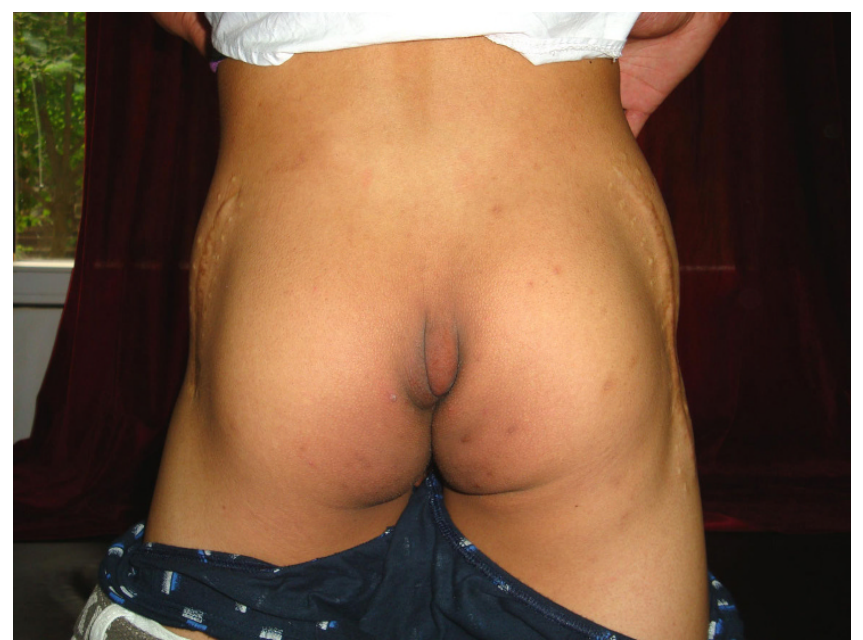

\section{Figure 3}

Level II patient form figure 2, The abduction contracture angle is $45^{\circ}$ with both hip and knee joint in $90^{\circ}$.

This patient came to our hospital for the second surgery due to the incomplete release of the contraction band in the other hospital. The huge scaring in the incision can also been seen.

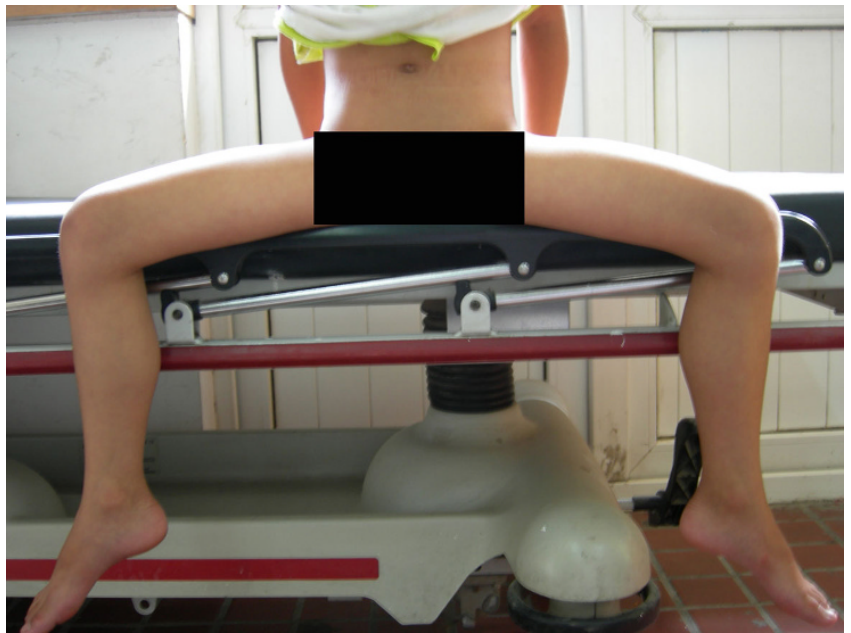

Figure 4

Level III patient, The abduction contracture angle is more than $60^{\circ}$ with both hip and knee joint in $90^{\circ}$.

This patient also has abduction disorders when the hip joint is not in flexion.

higher than in level II and III patients $(\mathrm{P}<.05)$. The effective rate of NOM in the level I group of children (13/19 [68.4\%]) was higher than in the adolescent group (5/15 [33.3\%]; $P<.05)$. Operative treatment was performed in 6 level I patients, 84 of 85 level II patients, and all level III patients. All patients had excellence or fair results, while none failed. The excellence rate was $83.7 \%$, with no statistical difference (Table 4 ). The excellence rate of operative management in the child group (63/129 [48.8\%]) was

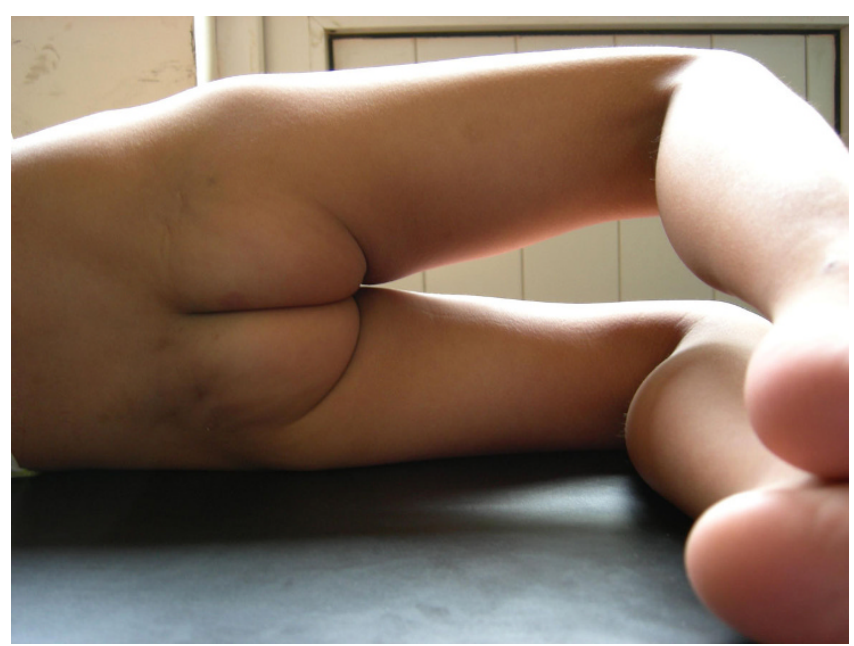

\section{Figure 5}

Level III patient from figure 4 , The abduction contracture angle is more than $60^{\circ}$ with both hip and knee joint in $90^{\circ}$. This patient also has abduction disorders when the hip joint is not in flexion. 
Table I: Classification of gluteal muscle contracture

\begin{tabular}{ll}
\hline Category according to level \\
$\begin{array}{ll}\text { Level I } \\
\text { (mild) }\end{array}$ & $\begin{array}{l}\text { The extorsion of lower limb is mild, the abduction contracture is less than } 15^{\circ} \text { with both hip and knee joint in } 90^{\circ} \text { of flexion or } \\
\text { adduction range is less than } 20^{\circ} \text { with no flexion. Ober's sign and frog squatting sign is weakly positive. The limp gait is not } \\
\text { apparent with lateral inclination of pelvis on anteroposterior radiograph being less than } 10^{\circ}\end{array}$ \\
$\begin{array}{l}\text { Level II } \\
\text { (moderate) }\end{array}$ & $\begin{array}{l}\text { The extorsion of lower limb is moderate, the abduction contracture ranges from } 15^{\circ} \text { to } 60^{\circ} \text { with both hip and knee joint in } 90^{\circ} \\
\text { of flexion or adduction range is less than } 10^{\circ} \text { with no flexion. Ober's sign and frog squatting sign is positive. The limp gait is } \\
\text { apparent with lateral inclination of pelvis on anteroposterior radiograph being less than } 20^{\circ}\end{array}$ \\
$\begin{array}{l}\text { Level III } \\
\text { (server) }\end{array}$ & $\begin{array}{l}\text { The extorsion of lower limb is severe, the abduction contracture is more than } 60^{\circ} \text { with both hip and knee joint in } 90^{\circ} \text { of flexion } \\
\text { or adduction range is less than } 0^{\circ} \text { with no flexion. Ober's sign and frog squatting sign is strongly positive. The limp gait is } \\
\text { remarkably apparent with lateral inclination of pelvis on anteroposterior radiograph being more than } 20^{\circ}\end{array}$
\end{tabular}

Category according to type

Type MA Gluteus maximus contraction type

Type MEI Gluteus medius and minimus contraction type

Type AGM Gluteus maximus, medius and minimus contraction type (All gluteal muscle contraction type)

higher than in the adolescent group (66/129 [51.2\%]; $P<$ $.05)$. No difference was seen between the different types with NOM or operation.

Complications after operative management only appeared in level II and III patients, and included scar swelling ( $\mathrm{II}=16 ; \mathrm{III}=48$ [some severe cases exceeded 0.7 $\mathrm{cm}]$ ), hematomas ( $\mathrm{III}=4)$, infections ( II = $1 ; \mathrm{III}=1)$, and wound dehiscence $(\mathrm{III}=1)$.

\section{Discussion}

Although several factors might be the cause of GMC, we found that repeated injections in the buttocks was perhaps the main cause from our previous epidemiologic survey, which was consistent with other reports $[9,10]$. For all of the patients in this study, 108 parents of the patients recalled repeated injection in the buttocks of their children at an early age; 5 parents denied injections in the but-

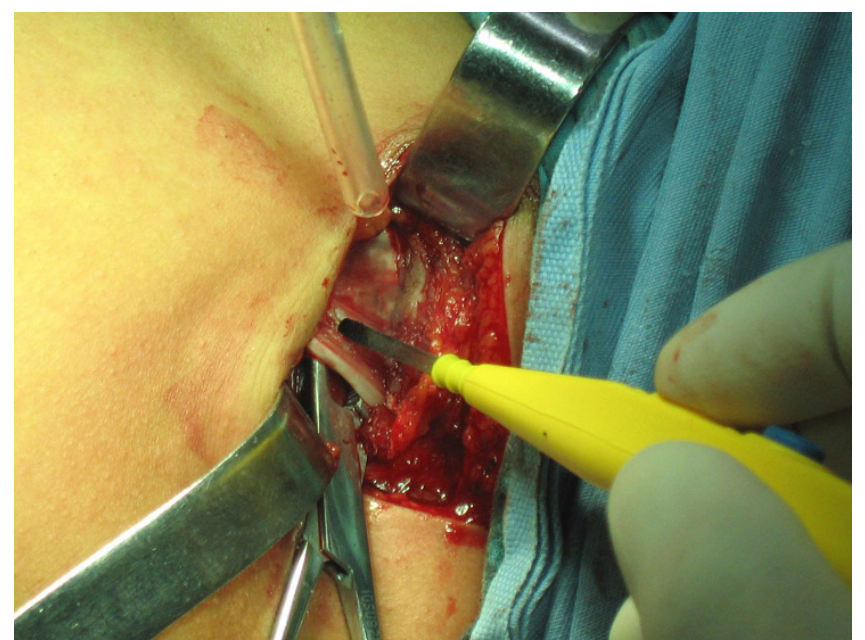

Figure 6

Intraoperative view of the lesion of contraction. tocks, and were thus idiopathic just as some other reports have suggested and it would take more effort for confirmation $[11,12]$. Two patients appeared to have a genetic tendency, as both the children and their fathers were diagnosed with GMC, although this possibility also needs further work to be identified. One patient was diagnosed with a fibroma in the left hip joint. The diagnosis of GMC mainly depends on anamnesis, and typical clinical manifestations; X-ray and MRI studies would not be requisite, but could always help eliminate other osteopathologic changes and make available additional information before surgery $[13,14]$.

Reasonable classification would help us to achieve a better understanding of pathologic features of this disease and indicate more suitable treatments. Previous studies have mainly focused on contracture of the gluteus maximus, which always included the most severe cases, or created a classification emphasizing the aesthetic aspects more than the functional aspects, and which would be helpful to plastic surgeons $[11,15,16]$. However, our classification system was based on all types of contractures with different levels focusing on functional and pathologic changes. Out of concern regarding clinical manifestations and anatomic changes, we proposed a classification scheme consisting of 3 levels and 3 types.

Table 2: Gluteal muscle contracture cases according to level and type

\begin{tabular}{lllll}
\hline & MA & MEI & AGM & Total \\
\hline Level I & 28 & 1 & 5 & $34(21.6)$ \\
Level II & 61 & 8 & 16 & $85(53.8)$ \\
Level III & 19 & 6 & 14 & $39(24.6)$ \\
\hline Total & $108(68.4)$ & $15(9.5)$ & $35(22.1)$ & $158(100)$ \\
\hline
\end{tabular}

Values are number (percentage). 
Table 3: Outcome of nonoperative management

\begin{tabular}{llll}
\hline & Effective & Failed & Effective rate \\
\hline $\begin{array}{lll}\text { Outcome according to level } \\
\text { Level I }\end{array}$ & 18 & 16 & $18 / 34(52.9)$ \\
Level II & 1 & 11 & $1 / 12(8.3)$ \\
Level III & 0 & 3 & $0 / 3(0.0)$ \\
Total & 19 & 30 & $19 / 49(38.8)$ \\
\hline Outcome according to type & & \\
MA & 17 & 22 & $17 / 39(43.4)$ \\
MEI & 0 & 2 & $0 / 2(0.0)$ \\
AGM & 2 & 6 & $2 / 8(25.0)$ \\
Total & 19 & 30 & $19 / 49(38.8)$ \\
\hline
\end{tabular}

Values are number (percentage).

Type MA only involves the gluteus maximus, so patients with this type would represent extorsion of the lower limb, adduction disorders when the hip joint is flexed, especially while sitting and squatting and with a limitation of flexion. The gluteus medius and minimus play an important role in abduction of the hip and it had functions of both extorsion and intorsion. Based on the location in which muscle injections are usually performed, it would only result in an extorsion abnormity. Therefore, contracture of the gluteus medius and minimus (type MI) would be in extorsion abnormalities, and adduction disorders, even without flexion and limp gait when the lesions on the two sides are not in parallel. Some patients with limp gait would appear to have an incline of the pelvis and compensatory scoliolosis. However, some reports have revealed that the lesion of their patients were only limited to the gluteus medius or gluteus minimus, leading to a disorder of limp gait, but we did not encounter such [17]. For type AGM, both two types of the clinical manifestations would appear.

Since Valderrama reported GMC in 1970, surgeons have deemed that operative management is an effective way to

Table 4: Outcome of operative management

\begin{tabular}{llll}
\hline & Excellent & Fair & Excellent rate \\
\hline $\begin{array}{l}\text { Outcome according to level } \\
\text { Level I }\end{array}$ & 6 & & \\
Level II & 71 & 0 & $6 / 6(100)$ \\
Level III & 31 & 13 & $71 / 84(84.5)$ \\
Total & 108 & 8 & $31 / 39(79.5)$ \\
& & 21 & $108 / 129(83.7)$ \\
\hline Outcome according to type & & \\
MA & 70 & 13 & $70 / 83(84.3)$ \\
MEI & 13 & 2 & $13 / 15(86.7)$ \\
AGM & 25 & 6 & $25 / 31(80.6)$ \\
Total & 108 & 21 & $108 / 129(83.7)$ \\
\hline
\end{tabular}

Values are number (percentage). cure the disorders, but in terms of NOM, most reports have concluded it to be invalid [18]. However, considering the patient's condition, which they cured and was relatively severe from the description, we still hold the opinion of giving a chance for patients with trivial function disorders. Thus, for all level I patients, we adopted a series of physiotherapies of NOM preferentially, and operative management would be offered afterwards in case that the situation did not improve or they insisted on better results [Table 5]. NOM was effective in one-half of the level I patients $(52.9 \%)$, but the situation in all effective cases was just improved, not totally recovered. This suggested the limitation of NOM in curing patients. However, with respect to the financial costs to some poor families, the mental stress of the child, and previous conditions, most parents and children themselves were satisfied with the outcomes. Those patients in whom the condition was not improved had been offered operative management afterwards (10 patients refused), and they all totally recovered. For patients in levels II and III, we give patients operative management directly. However, because of education and other matters, 12 patients in level II and 3 patients in level III postponed their operation. During the interval, they had NOM instead (approximately one-half year), and only 1 slightly improved, while the others totally failed. This result was significantly lower than the result of NOM in level I patients $(P<0.05)$. Nevertheless, the function of hip movement in level II and III patients with operative management improved considerably. Seventy-one of 84 level II patients and 31 of 39 level III patients got excellent results. This result, together with the result in NOM, indicated the necessity of operative management in levels II and III. The outcome of operative management had no statistical difference between the 3 levels and between the 3 types, which indicated us that operative management would be a perfect choice for any level or type of GMC patients. We found age was one important factor that influenced the results of both NOM and operative management. Patients in the child group gained better results than the adolescent group in both the treatments, which suggested the importance of earlier medical intervention.

The success of operative management rested in two points: 1) complete release of fibrotic tissue and 2) protection of intact tissue. Incomplete releasing would result in incomplete disappearance of complaints and physical sign, while excessive releasing would harm the stability of the hip joint which might lead to Trendelenburg gait. Six patients came to our department for a second operation and 2 patients for a third procedure; all of them were due to incomplete release. It was very important to check whether the Ober's sign is positive intraoperatively, especially in type MEI and AGM. 
Table 5: Recommendation of treatment strategy

\begin{tabular}{ll}
\hline Levels of Patients & Recommendation of treatment strategy \\
\hline Level I & $\begin{array}{l}\text { NOM as first choice, operation as recruitment treatment. Interogluteal incision or use arthroscopic technique is recommended. } \\
\text { Level II }\end{array}$ \\
$\begin{array}{l}\text { Operative management as first choice, NOM as choice for recruitment treatment for waiting for operation or after operation. } \\
\text { Surgeons could adopt interogluteal incision or use arthroscopic technique depending on the condition of patients. }\end{array}$ \\
$\begin{array}{l}\text { Operative management as first choice, NOM as choice for recruitment treatment for waiting for operation or after operation. } \\
\text { Operation under direct-viewing with conventional incision is commended, in order for complete releasing. }\end{array}$
\end{tabular}

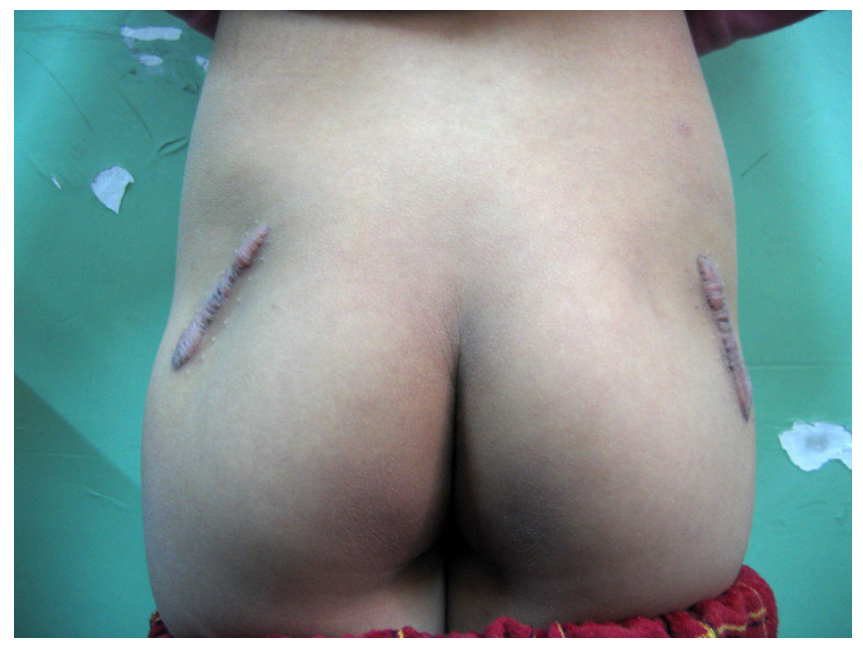

Figure 7

Hypertrophic scar of the incision in a GMC patient.

Until now, the operative strategy included a Z-plasty and simple releasing. Of all patients included in this study, only simple releasing operations were performed, thus further research is needed regarding which operative method is better. The most frequent complication was swelling of hypertrophic scars or keloids; 64 patients appeared visible (7 $\mathrm{mm}$ at most), which was in agreement with some other reports (Figure 7) [15,19]. Probable solutions to this problem would possibly be an intergluteal incision or using an arthroscopic technique $[16,20]$. As fibrosis of the gluteal muscle in GMC patients share the same pathologic changes with hypertrophic scars or keloids, that is, hyperplasia of fibrocytes and increased synthesis of extracellular matrix (ECM), including collagens. Thus, the association between fibrosis of the gluteal muscle and formation of hypertrophic scars or keloids in the incision need more research.

\section{Conclusion}

Our work is a retrospective study of gluteal muscle contractures in children. We proposed a detailed classification of GMC and have assessed the outcomes of different management techniques. NOM was more effective in level I patients than in level II and III patients. Operative management was valid in patients at all levels with no statisti- cal difference. We recommend NOM as primary treatment for level I patients and operative management for level II and III patients. Age was one important factor which influenced the final result, which suggested that either NOM or surgery should be carried out as early as possible.

\section{Competing interests}

The authors declare that they have no competing interests.

\section{Authors' contributions}

All authors read, edited, and approved the final manuscript. CGZ and XJH are the lead investigators, and developed the design of the study, carried out data-acquisition, analysis, interpretations, and prepared as primary authors for the manuscript. BL, HPL, and DW were responsible for the design, project supervision, and writing of the manuscript. ZZZ assisted in carrying out data acquisition and was involved in preparing the study design and in writing the manuscript.

\section{Acknowledgements}

This study was supported by a grant from The Food and Drug Administration of Shannxi Province (Y200 334002). Written consent for publication was obtained from the patients or their relatives.

\section{References}

I. Valderrama JAF: A cause of limited flexion and adduction of the hip in children. J Bone Joint Surg [Br] 1970, 52:179.

2. Howard RC: latrogenic quadriceps and gluteal fibrosis. J Bone Joint Surg [Br] 197I, 53:354.

3. Chigot PL, Vialas M: Fibroses rétractiles du moyen fessier. Rev Chir Orthop 1969, 55:154.

4. Motta A: La miosite fibrosa causa di limitazione articolare del ginocchion e dell'anca. Clin Ortop 1971, 23: I|4-121.

5. Henvkovský O: Progressive fibrosis of the vastus intermedius muscle in children. A cause of limited knee flexion and elevation of the patella. J Bone Joint Surg $[\mathrm{Br}]$ |96I, 43:3।8-325.

6. Williams PF: Quadriceps contracture. J Bone Joint Surg [Br] 1968, 50:278-284.

7. Fenollosa Gomez J, Quiles Galindo M: Retracción bilateral del gluteo mayor. Reo Ortop Traumat 1969, 13:701-708.

8. Karlen $A$ : Congenital fibrosis of the vastus intermedius muscle. J Bone Joint Surg [Br] 1964, 46:488-49I.

9. Mehta $\mathrm{MH}$ : Bilateral congenital contracture of the ilio-tibial tract. J Bone Joint Surg [Br] 1972, 54:532-534.

10. Hang YS: Contracture of the hip secondary to fibrosis of the gluteus maximus muscle. J Bone Joint Surg Am 1979, 6 I (I):52-55.

II. Brignall CG, Brown RM, Stainsby GD, et al.: Fibrosis of the gluteus maximus as cause of snapping hip. J Bone Joint Surg Am 1993, 75(6):909-910.

12. Shen YS: Abduction contracture of the hip in children. J Bone Joint Surg [Br] 1975, 57:463-465.

13. Cai JH, Gan LF, Zheng HL: lliac hyperdense line: a new radiographic sign of gluteal muscle contracture. Pediatr Radiol 2005, 35:995-997. 
14. Chen CK, Yeh L, Chang WN: MRI diagnosis of contracture of the gluteus maximus muscle. AJR Am J Roentgenol 2006, 187:169-I74.

15. Shen YS: Gluteus maximus contracture. Clin Orthop Relat Res 1982, 162:185-188.

16. Gonzalez R: Gluteal Retractions: Classification and treatment techniques. Aesthetic Surg J 2006, 26:537-550.

17. Yue $L$, Xinhua $P, K a i$ : Operative management for children with pelvic obliquity caused by gluteal muscle contracture. Chin J Pediatr Surg 2005, 26:590-592.

18. Valderrama JAF, Miguel RE: Fibrosis of the gluteus maximus: a cause of limited flexion and adduction of the hip in children. Clin Orthop Relat Res 198I, I 56:67-78.

19. Peiro A, Fernandez Cl, Gomar F: Gluteal fibrosis. J Bone and Joint Surg [Am] 1975, 57:987-990.

20. Liu YJ, Wang Y, Xue J, et al.: Arthroscopic gluteal muscle contracture release with radiofrequency energy. Clin Orthop Relat Res 2009, 467(3):799-804.

\section{Pre-publication history}

The pre-publication history for this paper can be accessed here:

http://www.biomedcentral.com/1471-2474/10/34/pre

pub

Publish with Bio Med Central and every scientist can read your work free of charge

"BioMed Central will be the most significant development for disseminating the results of biomedical research in our lifetime. "

Sir Paul Nurse, Cancer Research UK

Your research papers will be:

- available free of charge to the entire biomedical community

- peer reviewed and published immediately upon acceptance

- cited in PubMed and archived on PubMed Central

- yours - you keep the copyright

Submit your manuscript here:

http://www.biomedcentral.com/info/publishing_adv.asp 